\title{
Environmental Engineering Program Preparing Engineers to Tackle New Challenges
}

\author{
Claudio da Rocha Brito \\ President \\ Science and Education Research Council - COPEC \\ São Paulo, Brazil \\ E-mail: cdrbrito@copec.org.br
}

\author{
Rosa M. Vasconcelos \\ President \\ Pedagogical Council - University of Minho \\ Guimarães, Portugal \\ E-mail: rosa@,det.uminho.pt
}

\author{
Melany M. Ciampi \\ President \\ Safety, Health and Environment Research Org. - SHERO \\ São Paulo, Brazil \\ E-mail: melany@,copec.org.br
}

\author{
Luis A. Amaral \\ President \\ Computer Graphics Center - CCG \\ Guimarães, PORTUGAL \\ E-mail: amaral@des.uminho.pt
}

\author{
Victor F. A. Barros \\ Executive Secretary \\ Science and Education Research Council - COPEC \\ São Paulo, BRAZIL \\ E-mail: victor@,copec.org.br
}

\begin{abstract}
The Engineering Education Research Team of COPEC - Science and Education Research Council has designed and is implementing a program for an engineering school which main goal is to offer a PhD program of high quality in order to fulfill the work market demand for a high qualified environmental engineer. It is an interdisciplinary environmental engineering program that intends to offer students an exciting opportunity to focus their technical capabilities on evolving science that affects human quality of life in a global scale and can simultaneously help preserve and restore areas in which they work. Following the world trend educational model of theory and practice, student projects provide unique, hands-on opportunities to explore the multifaceted considerations surrounding environmental engineering problems on local and global levels, and to improve living conditions in the subject areas. It has a curriculum that addresses the time-crunch problem by integrating professional practices into the technical curriculum.
\end{abstract}

Keywords - global education perspective; PhD program; technical skills; regional environmental issues; growing economies.

\section{INTRODUCTION}

Examining more carefully the training of engineers, it is assumed that technical skill is associated with understanding and proficiency in a particular type of activity, especially those that are involved in methods, processes and procedures. As an example, one can take the training of the engineer, who mostly - is focused on calculations, simulations and projects, characterizing it as an individual, above all, objective. Since the human ability can be understood as the ability of individuals to interact with others and respect fellows and nature, these individuals are aware of their own attitudes, opinions and beliefs on others.

Realizing the existence of other attitudes, opinions and beliefs different from his/hers, the individual is able to understand others. By becoming aware of the need to combine their technical skills (to run its specific activity) with the human ability (to develop proactive human relationships), this professional develops the conceptual ability, which is directly associated with the coordination and integration of all attitudes and interests of the organization that owns or provides the service. In other words, the professional will not be technical enough to be good, if he/she is not able to understand comprehensively the meaning of the activity, which is being exerted through these three interconnected skills. This aspect is the main one in terms of engineering education for 21 st century labor market for engineers.

The goal of this work is to show the engineering program developed with the objective to train engineers to enter and remain in the future labor market [1]. The choice of a $\mathrm{PhD}$ program is due to the investments that are being done in region and the future possibilities for civil engineers. It is a region where petrol has been found in a great amount and also where the enlargement of the seaport for 2020 is being planned, two big endeavors that require many constructions. This is the opportunity for young people who are seeking for a career and a job. 


\section{GLOBAL ENVIRONMENT ECONOMY AND DEVELOPMENT}

In according to Doaa Abdel Motaal a deputy chief staff of the World Trade Organization environment has two views: the environmentalists' point of view: to environmentalists, the green economy means greening and making more sustainable the production and supply chains as well as the consumption patterns; to the majority of the politicians, on the other hand, the green economy means the competition for green jobs; in other words, with the desire to keep whatever new jobs the green economy generates within territorial boundaries and to protect these jobs as much as possible once they come about. Given these radically different goals, confusion can emerge over industrial policy and environmental policy associated with green jobs.

In the pursuing of creating green jobs politicians should only set environmental targets and then let markets do their job. In the renewable-energy sector, for example more jobs are created in the actual deployment of clean energy - jobs which by definition can only be local - than are created in manufacture.

The point is that it is a global economy and the governments should focus in taking advantage of this kind of economy and generates opportunities for locals. In according to Yale Global protectionist policies inevitably threaten trade cooperation, jobs and the environment.

It is possible to provide green jobs opportunities in every level just boosting the pursuing for sustainable green development.

\section{Global Perspective FOR ENGINEERING Programs}

The present work market in general is extremely complex and demanding for both professionals and enterprises, and mainly to the educational institutions - the universities - that prepare the high qualified professional. In the engineering field, the challenges are enormous. It became more and more necessary to prepare the engineer for a much more changing world full of complex issues of global and regional dimensions.

For engineering colleges the task is huge, once it is imperative to deliver a professional capable above all to enter and keep up with the work market, working in companies, in governmental organizations, as entrepreneur, or consultant.

The actions towards the quality of a program have to be taken by the engineering college members responsible for the creation and development of an engineering program that fits the new demands. It is necessary to:

- create a balanced program that integrates technical skills and professional practices;

- provide professional development and opportunities that enable faculty to teach effectively in an integrated curriculum;

- implement an integrated curriculum that meets diverse student populations;

- develop a rigorous assessment program that balances indirect and direct measures;
- establish and maintain an active research community with a research agenda that completes a feedback loop to strengthen engineering.

It is generally agreed that the engineers that universities train gain tremendous professional advantages if they write and speak well, work in teams and manage projects effectively, and listen carefully. Their communication needs to be technically complete and accurate, logically organized for the audience, visually appealing, and interesting; it also needs to be mechanically and grammatically conventional, and it must say something worthwhile. This is the recipe for success in any field and so any engineering program should include courses to enhance these skills.

\section{ENVIRONMENTAL ENGINEERING PROGRAM DEVELOPED BY ENGINEERING EDUCATION RESEARCH TEAM OF COPEC}

Environmental Engineering helps make the air, waters, and land better and safer for humans. Work includes designing, building, and operating systems to manage wastewater, cut air pollution, improve solid-waste disposal, and make recycling more cost-effective. Engineers also find ways to reduce emissions from vehicles and power plants, and clean up toxicwaste sites. Efforts are guided by environmental law, regulators, and public health concerns, spelled out in environmental-impact statements.

Taking it into account the Engineering Education Research Team of COPEC - Science and Education Research Council has designed a program for an engineering school which main goal is to prepare engineers for the future work market, the engineer for the future. The program has been designed in detail in accordance to the present labor market of engineers, with its particular characteristics and considering a growing need for engineers. The success of the program depends on the ability to inspire the students by showing engineering as an exciting career, a personal upward path, and a way to affect local social and economic well-being. The implementation of the program is meant to 2014 .

\section{MAIN ASPECTS OF THE PROGRAM}

It is an interdisciplinary environmental engineering program that intends to offer students an exciting opportunity to focus their technical capabilities on evolving science that affects human quality of life in a global scale and can simultaneously help preserve and restore areas in which they work. Emerging issues challenge environmental engineers in public health, conservation and restoration of natural systems, water and wastewater treatment, pollution prevention, and more. Students in this program gain the professional skills to manage these complex issues and help their planet.

It is a $\mathrm{PhD}$ level program with topics for research ranging from power storage to water quality preservation, and opportunities to work in outdoor settings and communities as well as in laboratories. Following the world trend educational model of theory and practice, student projects provide unique, hands-on opportunities to explore the multifaceted considerations surrounding environmental engineering 
problems on local and global levels, and to improve living conditions in the subject areas.

It offers a unique depth in this specialization, with educational options that supply the comprehensive understanding swiftly transforming field demands. It is a fulltime $\mathrm{PhD}$ program that lasts two years, offering classes conducted on an undergraduate-type schedule.

It has a curriculum that addresses the time-crunch problem by integrating professional practices into the technical curriculum - that is, professional practices are contextualized in engineering in ways that reinforce and strengthen students' understanding and their ability to apply that understanding to address engineering problems. Throughout their graduate program, students work to master the engineering body of knowledge and simultaneously become skillful communicators, ethical decision makers, team leaders, creative thinkers and problem solvers.

Today, engineers must keep up with emerging technologies and understand the financial and strategic impact of their decisions. The program strongly focuses in career development fostering the accumulation and cultivation of skills and knowledge that enable a professional to advance or grow in the field of his or her choice.

The two-year program (120 ECTS) consists of courses amounting to 90 ECTS, followed by a Degree project (30 ECTS). The system is compatible with ECTS credits, the European credit system. Although the system of the country is in credit hours, the choice of having the European credit system is due to the fact that it is a trend for the future. It makes no difference as in terms of credit hours the amount is in accordance with the demands of the Ministry of Education.

At the end of the program the students receive a diploma registered and recognized by the Ministry of Education of the Country.

\section{THE COURSES}

The choice of courses is based on the global and regional demand for engineers capable to work in projects taking into account the environmental issues and to enhance the practice of engineering for the betterment of whole community, nature and human groups impacted by projects.

The courses are dimensioned to explore the content pertinent for the development of a mind focused on research.

The courses are as follows:

ENVIRONMENTAL STUDIES: The study of environmental problems and their solutions requires an interdisciplinary approach. This course examines current environmental issues from the intersection of several key disciplines including: environmental philosophy and history, environmental policy, and science. The course develops these different approaches for analyzing environmental problems, explore the tensions between them, and present a framework for integrating them. Topics such as environmental justice, developing nations, globalization, and climate change policy are explored.
GEOGRAPHIC INFORMATION SYSTEMS: This course introduces Geographic Information Systems (GIS) as a powerful mapping and analytical tool. Topics include GIS data structure, map projections, and fundamental GIS techniques for spatial analysis. Laboratory exercises concentrate on applying concepts presented in lectures and focuses on developing practical skills. These exercises include examples of GIS applications in environmental modeling, socio-demographic change and site suitability analyses. Although the course is computer-intensive, no programming background is required.

ENVIRONMENTAL POLICY AND ETHICS: In this course, we will examine some of the important moral, legal, and public policy concerns which are raised by the interaction of human beings with the natural environment. How are policy frameworks, the beliefs and actions of environmental activists, and your views guided by deep seated notions of who has standing in the moral community? The course considers a range of moral perspectives including: anthropocentrism, biocentrism, egocentrism, animal rights and others, and examines them in the context of various contemporary public policy case studies [2].

GOVERNANCE, TECHNOLOGY, AND INNOVATION: This course examines how public policy models have the capacity to shape technological change and social innovation in a time of ecological crisis. With global attention dominated by environmental catastrophe and despair, it spotlights new work that has brought together scientists, environmentalists, engineers, and artists to tackle the most serious problems facing communities. It explores the political ecology implications of control over essential resources and the positive consequences of rethinking and democratizing basic social needs for a more sustainable future [3]. Recent exciting case studies feature examples of simple solutions that inspire elegant, transferrable, and inexpensive applications of technological design. It examines the role and obligation that scientists have to collaborate with interdisciplinary and public policy efforts that benefit people with sustainable approaches to architecture, food, energy, transportation, and infrastructure.

HUMAN BEHAVIOR AND ENVIRONMENTAL PROBLEMS: This course examines how people think about and behave toward the environment. Environmental problems can ultimately be attributed to the environmental decisions and actions of human beings. These behaviors can in turn be understood as resulting from the nature and limitations of the human mind and the social context in which behavior takes place. Knowledge of the root causes of environmentally harmful behavior is essential for designing effective solutions to environmental problems. The goals of the course are:

- to provide students with the basic social science knowledge needed to understand and evaluate the behavioral aspects of such important environmental problems as air and water pollution, global warming, ozone depletion, preserving biological diversity, and hazardous waste and

- to help students identify and improve shortcomings in their knowledge and decisions related to the environment. 
Topics include, but are not limited to:

- environmental problems as tragedies of the commons;

- public understanding of global warming and global climate modeling;

- folk biology;

- risk perception;

- intelligent criticism of environmental claims;

- making effective environmental choices;

- strategies for promoting pro-environmental behavior;

- human ability to model and manage the global environmental future.

ENVIRONMENTAL PROBLEMS IN GROWING ECONOMIES: Environment and development are often seen as incompatible, in part because many poor people in the developing world depend directly on natural resources for their livelihoods. At the same time, poor people are often seen as responsible for causing environmental degradation because they lack the knowledge, skills and resources to manage the environment effectively. The vicious circle is completed as environmental degradation exacerbates poverty. However, optimists argue that poor people can and do contribute positively to environmental outcomes, that states and organizations can facilitate their efforts and that environmental interventions can coincide with development [4]. This course examines these different perspectives on environmental problems in the developing world through the insights and critiques of social science. Subjects covered include sustainable development, population, environmental risks, gender, urbanization, environmental decision-making and nongovernmental organizations (NGOs). The goals of this course are to think critically about the various links between environment and development and the role of governmental and non-governmental organizations in promoting sustainable development in the developing world.

ENVIRONMENT \& RISK COMMUNICATION: Environmental risks consist of incidents or trends, either manmade or natural in cause, that have potential to inflict harm to human health and/or ecosystems and could include physical assets or the economy (i.e., business and social disruption). Communication of environmental risks can be divided into two distinct categories, according to the time-sensitivity of the need for sharing information:

- events that might occur in the future where prevention is the focus, and

- emergency scenarios where an event has occurred, and there is a need for immediate notification and deployment of mitigation actions.

Moreover, the consequences of these events can produce either acute or chronic effects. The communication process is at the heart of effective environmental risk communication because it establishes the policies and procedures under which individuals and organizations will operate. Another requirement for effective communication is the ability to disseminate risk information in a timely, reliable and targeted manner. Reaching the proper audience through the proper means at the proper time is a prerequisite to effective environmental risk communication [5]. This course examines the needs of an effective communication in case of environmental risks. It provides a series of case studies in order to allow students to acquire knowledge on effective ways of communications in case of environmental risks to the wide environmental risk stakeholders.

ORIENTED CAREER DEVELOPMENT: Reflect, plan and chart a future career becomes vital condition for professional success in a globalized world. Plan a career is not just choosing a profession or an undergraduate course to follow, but also an industry segment and a performance for which the young or trader should prepare by preparing himself/herself with all the necessary tools that will bring competitive desired expertise and differential [6]. The goal of this course is to foster students with the search for career development in terms of niche choice and entrepreneurial initiatives.

ENVIRONMENTAL STUDIES SEMINAR: The course is designed to integrate each student's educational experience (e.g., core environmental courses, environmental electives, and environmental projects) in a capstone seminar in Environmental Studies. Through seminar discussions and writing assignments students will critically reflect on what they learned in their previous courses and project experiences. In teams, students will prepare a final paper and presentation that critically engages their educational experience in environmental studies and anticipates how their courses and experiences will translate into their future personal and professional environmental experiences.

The content delivery of each course is up to the teacher who can sense the development of the students and make adjustments in order to cover the topics. The choice for this more liberal approach aims to provide the students with comprehension and application of the learnt concepts in practical works [7].

\section{PROGRAM GOALS}

The goals of the program are to position graduates to:

- use their knowledge and understanding of engineering sciences and design to advance their professional career;

- think critically when solving and managing tasks;

- communicate effectively in multidisciplinary, professional environments;

- exercise professional responsibility and sensitivity in the context of the social, economic, ethical and environmental implications of their engineering work;

- function effectively and efficiently as an individual and as a part of a team; and

- pursue life-long learning to earn relevant professional credentials. 


\section{FINAL CONSIDERATIONS}

This is a world of challenging quick changes that are shaping a new kind of professionals in every field. Competence and willing to accept challenges in the work environment are now the rule of the rules, a professional must keep up with new technologies and technics available and that emerge every day. There is no recipe to acquire knowledge of last technological development and so a way to achieve this is to become a compulsory researcher and have open mind for lifelong education. Leave behind the prejudice of too old to be in classroom.

No matter the field, professionals must pursue productivity and high performance in order to enter and to maintain in the present work market. Although countries around the world are experiencing a shortage of engineers, for engineers it is also a fact that companies are hiring and keeping few however good engineers, which are committed with the organizations values and possess high technical skills, among others. These are requirements on top of writing skills, speaking other languages with some proficiency, work in teams, manage projects effectively and listen carefully.

The described program offers the possibility for the students hands-on work and case studies due to the current regional scenario and the geographical location in the country besides belonging to a historical moment of a growing economy country.

The main objective of the program is the offer of a $\mathrm{PhD}$ program of high quality in order to fulfill the work market demand that encounters the historical moment of the region that is requiring more.

\section{ACKNOWLEDGMENT}

This work was partly funded by FEDER funds through the Operational Competitiveness Program (COMPETE) and by FCT with the projects PEst-C/CTM/UI0264/2011 and FCOMP-01-0124-FEDER-022674.

\section{REFERENCES}

[1] Brito, C. da R.; Ciampi, M. M. Forming Engineers for a growing demand. In: International Conference on Engineering and Computer Education, 8., Luanda, 2013. Forming Engineers for a growing demand. Luanda: ICECE, 2013

[2] Brito, C. da R.; Ciampi, M. M. Engineers for global market: Preparing the future. In: SEFI Annual Conference, 39. Lisbon, 2011. Global Engineering Recognition, Sustainability and Mobility. Lisbon: SEFI, 2011.

[3] Brito, C. da R.; Ciampi, M. M. Frontiers of engineering: Opportunity and challenges. In: ASEE/IEEE Frontiers of Education Conference, 41. Rapid City, 2011. Celebrating 41 Years of Monumental Innovations from Around the World. Rapid City: FIE, 2011.

[4] Brito, C. da R.; Ciampi, M. M.; Amaral, L.; Vasconcelos, R Engineering and technology education turning challenges into opportunities. In International Conference on Engineering and Technology Education, 12., East Timor, 2012. Engineering and Technology Education Turning Challenges into Opportunities. East Timor: INTERTECH, 2012.

[5] Brito, C. da R.; Ciampi, M. M.; Amaral, L.; Vasconcelos, R Engineering education for the improvement of practice: Preparing for labour market. In: ASEE Annual Conference, 119., San Antonio, 2012. Proceedings. San Antonio: ASEE, 2012.

[6] Brito, C. da R.; Ciampi, M. M. Engineering 2020: Preparing the future. In: IGIP Annual Symposium, 41., Vilach, 2012. Collaborative Learning and New Pedagogical Approaches in Engineering Education. Villach: IGIP, 2012.

[7] http://yaleglobal.yale.edu/content/quest-green-jobs 